\title{
COMUNICACIÓN NOMADOLÓGICA. DE LA IDENTIDAD A \\ LA ALTERIDAD
}

\section{COMMUNICATION NOMADOLÓGICA. IDENTITY TO}

\section{ALTERITY}

\begin{abstract}
AUTOR
Claudio Andrés Maldonado Rivera. Asesor Educacional en Lenguaje y Comunicación. Universidad Católica de Temuco. Temuco (Chile).

cmaldonado@proyectos.uct.cl
\end{abstract}

\section{RESUMEN}

¿Por qué comunicar desde la nomadología? ¿Por qué desplazarse y ser otro al comunicar? ¿Frente a qué desplazarse y por qué ser otro comunicante?

Estas interrogantes promueven generar algunas reflexiones sobre el rol de la comunicación en la construcción de la identidad y la alteridad, dicotomía cruzada por la praxis del poder.

Comunicar desde la nomadología es una reflexión metateórica respecto a las posibilidades de desnudar los sistemas de significación endógenos, a modo de desplazarse, insurrectamente, a los márgenes de la semiósfera y su cruce con la otredad. Comunicar desde la nomadología es una apuesta por repensarnos comunicacionalmente, es transitar de la identidad a la alteridad para su junción, asumiendo un posicionamiento político al respecto.

\section{PALABRAS CLAVE}

Comunicación - Nomadología - Semiósfera- Identidad - Alteridad.

\begin{abstract}
Why communicating from the nomadology? Why scroll and be another to communicate? Against which scroll and why to be another communicating?

The questions intentions reflection on the role of communication in the construction of the identity and the alterity, dichotomy crossed which the exercise of power.

Communicate from the nomadology is a methateoretical reflection that aims to reveal the endogeneous codes, with the intention of moving, insurgent, the margins and the junction semiosphere alterity.
\end{abstract}


Communicate from the nomadology commitment to rethink communication with the difference, moving from identity to alterity betting on the merger, assuming a political position in this regard

\title{
KEY WORDS
}

Communication - Nomadology - Semiosphere - Identity - Alterity .

\section{ÍNDICE}

\author{
1. INTRODUCCIÓN. \\ 2. SOBRE LA NOMADOLOGÍA. \\ 3. EL TRIÁNGULO INFERNAL Y EL PROYECTO NOMADOLÓGICO. \\ 4. ANTROPOFAGIA CULTURAL. \\ ․ 5. APORTES DE LA ECONOMÍA POLÍTICA DE LA COMUNICACIÓN. \\ ^ 6. REARMANDO EL TRIÁNGULO INFERNAL.
}

\section{INTRODUCCIÓN}

En los campos disciplinarios de la comunicación, la problemática del encuentro con la otredad se torna un fenómeno de impronta, sobre todo si se asume en el contexto de un mundo globalizado que permite superar el distanciamiento territorial, generando una interacción permanente con sistemas culturales heterogéneos, los cuales, en el marco de una sociedad que rinde tributo a la tecnologización de las comunicaciones, se torna mucho más evidente.

Transitar hacia el otro es un desafío por resignificar las propias matrices culturales, las que estancadas en la norma de la identidad esencialista suelen restringir el devenir serotro en la comunicación, circunscribiendo el espacio interaccional -propio de la comunicación- a una pugna entre simbólicas que rigen el imaginario sociocultural de la propia identidad y del sujeto de la alteridad.

El comunicar desde el myself es asumir al otro como un extraño, sujeto exótico que tiende a corromper la representación autofundada del yo-nosotros, heredero de una semiósfera (Lotman, 1996) constituida por la historia, lo político, lo económico y lo cultural. El comunicar desde el myself es un modo de racismo cuyas máscaras se develan en el discurso proyectado desde dimensiones comunicativas diversas, que van desde el plano (inter)personal, massmediático e institucional (Van Dijk, 2003)

Abordar esta problemática, evidentemente, sitúa el estudio en el ámbito de la comunicación intercultural, la cual, siguiendo a Del Valle (2004a) debe comprenderse en el eje funcional de la resolución de conflictos por parte de los Estados nacionales, por 
tanto tiende a concebirse como una praxis sociopolítica y económica frente a la otredad supeditada a la dominación efectuada por la hegemonía cultural. Indagar en esta área de la comunicación es transitar tanto por lo político como por lo semiótico.

Al respecto, el mismo autor establece que el estudio de lo intercultural responde a dos ejes rectores: a) como hecho territorial y político; b) como hecho discursivo y simbólico (Del Valle, 2004a:172)

En este sentido, el comunicar nomadológico es una apuesta por repensar la situación de lo intercultural en el contexto de una realidad sostenida en prácticas de dominación/exclusión de la alteridad. Es asumir un ser-otro que se torna múltiple y heterogéneo en la interacción con la alteridad, que es parte de la propia identidad conformada en un continuo interaccional. El comunicar nomadológico es un desafío político y semiótico que reflexiona sobre el ejercicio del poder, por ende intenciona un ser comunicante consciente de su espacio de enunciación, de las prácticas institucionales, de los dispositivos semióticos que entretejen los estados del mundo simbólico que lo han determinado a ser un no-otro, un mismo en permanente determinismo. Comunicar desde la nomadología es aceptar la identidad y la alteridad como dos espacios semióticos que desde la diferencia articulan un nuevo modo de ser sujeto político en y de la comunicación.

\section{SOBRE LA NOMADOLOGÍA.}

En el esfuerzo por configurar un sistema metateórico que sustente la propuesta de la comunicación nomadológica, es necesario establecer bases teórico-conceptuales que direccionen el diseño de esta apuesta. Para tal empresa, la revisión del Tratado de nomadología escrito por Deleuze y Guattari (2002) otorga las primeras claves. No obstante, antes de adentrarnos en los conceptos que en esa meseta se abordan, se propone revisar con antelación los principios del rizoma expuestos en la Introducción, a modo de generar interconexiones conceptuales que permitan concebir de modo más amplio la comunicación nomadológica.

El rizoma es un pensar desafiante al binarismo reduccionista de Occidente, por tanto es la aceptación de la multiplicidad, un devenir permanente que aboga por la transmutación de los espacios de sentidos reglamentados por una lectura unidireccional, líneas de huída para la conformación de nuevos agenciamientos en apertura permanente. Sin embargo, tal como señalan los autores, estas ideas no convencerán a nadie "si no enumeramos algunos caracteres generales del rizoma" (Deleuze y Guattari, 2002:13).

De este modo, establecen 4 principios para comprender el rizoma:

- $1^{\mathrm{o}}$ y $2^{\mathrm{o}}$ : Principios de conexión y heterogeneidad. 
- $3^{\circ}$ : Principio de multiplicidad.

- $4^{\circ}$ : Principio de ruptura asignificante. (Deleuze y Guattari, 2002:13-15)

En un trazado escritural, los fundamentos de cada uno de estos principios son comprendidos del siguiente modo: $1^{\circ}$ y $\left.2^{\circ}\right)_{-}$el rizoma se concibe en su proyección con la multiplicidad de sistemas semióticos que cobijan la conexión de lo diferente, eslabón de heterogeneidades que ponen en tela de juicio los estamentos que rigen el orden de la realidad instituida desde la visión unívoca; $\left.3^{\circ}\right)_{\text {_ }}$ El rizoma es el agenciamiento del cambio permanente, en la medida que se dispone a la interacción con líneas de escape que derogan la homogeneidad, generando acoplamientos sígnicos con el afuera, en el encuentro con aquello que permite la resignificación de lo ya pre-establecido. Es un proceso de semiosis fundado en la multiplicidad; $4^{\circ}$ ) El rizoma, no obstante, puede estar sujeto a su delimitación producto de las fuerzas de estancamiento, sin embargo éste tiene la capacidad de resurgir desde un nuevo estadio de relaciones, tácticas estratégicas que permiten el desarrollo constante de nuevos trazos frente a las rupturas de su recorrido insurrecto.

A partir de estos principios, la noción de nomadología puede ser abordada de manera más esclarecedora.

Partamos señalando que el nómade es el sujeto que opera rizomáticamente a modo de contrarrestar las fuerzas delimitativas que impone el esencialismo estaticista. Es un yo que es otro al transitar por la heterogeneidad de sistemas significacionales, una especie de poeta maldito -recordando a Rimbaud con su frase Yo es Otro- que traspasa los límites regulativos del orden establecido, accediendo a lo inefable, al sistema de relaciones que se ha ocultado por la segmentariedad, islotes fragmentarios en los cuales habitamos.

El nómade manifiesta la posibilidad de asumir un modelo de ser-otro que transgrede todo aparato de control, principalmente en la lucha contra las imposiciones simbólicas del Estado, concebido por Deleuze y Guattari (2002) como un dispositivo coercitivo que tiende a deslegitimar al nómade, al guerrero desafiante de sus "estructuras estructurantes" y de sus "instrumentos de dominación" (Bourdieu, 2000). El nómade se ve sometido al levantamiento de discursividades que tienden a establecer una lectura deslegitimada de sus performance y su actitud ante el entorno:" desde el punto de vista del Estado, la originalidad del hombre de guerra, su excentricidad, aparece necesariamente bajo una forma negativa: estupidez, deformidad, locura, ilegitimidad, usurpación, pecado" (Deleuze y Guattari, 2002:361). Por tanto es un anhelo de ruptura frente al deseo de construcción rizomática del sujeto nómade. Sin embargo, su posibilidad de redireccionar su desplazamiento a lo heterogéneo subsiste como pasión de un querer ser otro. Todo querer -desde una semiótica de las pasiones- "es una apertura que actualizará el efecto de apuntar a un objetivo" (Greimas y Fontanille, 2000:33), pero al cual se le exige contrarrestar el diseño del "deber" institucional, el cual 
pretende establecer la "suspensión del devenir" (Greimas y Fontanille, 2000:34). Confrontación entre los organismos reguladores del cuerpo y la vida, frente a un cuerpo que busca remirar su orgánica esencialista para ser órgano en órganos.

Son estas luchas las que permiten comprender al nómade como una "máquina de guerra" (Deleuze y Cuattari, 2002), la cual genera una: "indisciplina fundamental del guerrero, una apuesta en tela de juicio de la jerarquía, un perpetuo chantaje al abandono y la traición, un sentido del honor muy perceptible, y que impide, una vez más, la formación del Estado" (2002:366).

Lo anterior, entiéndase como el deseo de transmutación de la "forma-Estado" (Deleuze y Guattari, 2002:366), lo que torna al nómade en una máquina de guerra que se conflictúa tanto con lo político como con la política: Lo político (entendido como una instancia antropológicamente originaria y socialmente fundacional, es decir como espacio de una ontología práctica del conjunto de los ciudadanos (...)) y la política (entendida como ejercicio de una profesión específica de los límites institucionales definidos por el espacio estático del Estado jurídico) (Grüner, 2002:21).

En este sentido, el nómade es un factor esencial para repensar la política desde lo político y viceversa, situándose en el margen y en los espacios exteriores a la tragedia fundacional del orden impuesto.

Tal situación adquiere realces sustanciales al introducir el tratamiento del otroalteridad, constituido en la génesis misma de lo político como ley de lo universal que se impone a través de un recorrido antirrizomático. Lo político como antinomadología materializada por las voces de la política.

Grüner, basándose en los análisis de Scmith $(1983 ; 1974)^{1}$, sintetiza la concepción de lo político en cinco puntos centrales, que a continuación pasan por un nuevo proceso de síntesis:

- Lo político remite a la posición dicotómica amigo/enemigo;

- Lo político se traduce en la militarización de la política;

- Lo político emerge en el estado de excepción;

- Lo anterior se configura a partir de la decisión soberana;

- Lo político supone una democracia auténtica, puesto que requiere de la voluntad de las masas. (Grüner, 2002:26)

Se infiere de estos puntos que lo político establece una violencia frente al otro desde su concepción fundacional, fuerza proyectada en la forma de concebir lo político y su materialización en la política.

1 Las obras a las cuales se remite el análisis son: Schmitt, Carl, 1974. Teología Política. Madrid: Guadarrama; Schmitt, Carl, 1983. El Concepto de lo Político. Madrid: Alianza. 
Es por tales motivos que la comunicación nomadológica debe insertarse en una lucha que sea capaz de plantear un nuevo modo de pensar lo político y hacer política, siendo lo comunicacional una herramienta que permita establecer formas innovadoras para emplazarse en el marco de una cultura global que remece los esencialismos identitarios. En esta línea se reconoce el trabajo de Domique Wolton (2004), quien apuesta por redirigir la influencia de la política en lo que denomina el "triángulo infernal: Identidad - Cultura - Comunicación" (Wolton, 2004:14).

\section{EL TRIÁNGULO INFERNAL Y EL PROYECTO NOMADOLÓGICO.}

La insurrección del nómade no es un libertinaje sin sentido, por el contrario, es el agenciamiento de un modo de ser-otro que se acopla a un proyecto estructural de corte comunicacional, cultural, identitario y, por supuesto, político.

El nómade en su reacción insurrecta frente a las regulaciones del Estado-nación, de los símbolos caducos por la uniformidad generada por la tradición del myself, se sitúa en un espacio descolonizante que apuesta por el sentido de lucha frente a las prácticas hegemónicas referidas a la construcción de la identidad y la alteridad dentro de un mundo colonial confeccionado en "compartimentos" (Fanon, 2009:32). Quien se asume en el proyecto de la comunicación nomadológica establece una apuesta por la legitimación de la alteridad como factor intrínseco al develamiento de la propia identidad. Empero, el problema central de esta mutación ontológica, axiológica, epistemológica y, claro está, ideológica, es que toda práctica de redefinición del individuo debe someterse a un proyecto que trascienda el plano individual y se inserte en el imaginario colectivo y sus prácticas. Es por tal motivo que se advierte que lo comunicacional, lo identitario y lo cultural no puede estar al margen de la político como instancia de regulación de pautas que activen a un sujeto de la comunicación que asume su interacción desde la reciprocidad y la aceptación de la diferencia.

En el proyecto de una transformación sustancial de los modos de ser comunicantes, Wolton elabora una línea de trabajo que intenciona repensar el quehacer de la política por ende también lo político- respecto al triángulo infernal, propuesta fundamental en el marco de una aldea global que conlleva a la convivencia cultural, pero que no ha sido capaz de establecer un proyecto político democrático al respecto.

Wolton apunta: La convivencia cultural nos pone sobre el filo de la navaja. O bien el vínculo con un proyecto político democrático puede establecerse, y de ese modo se logrará instalar un modelo de comunicación cultural relativamente pacífico; o bien no es posible tender el puente entre convivencia y proyecto político y triunfará entonces todos los irredementismos culturales. En un caso, la identidad se enlaza a un proyecto democrático de convivencia; en el otro, la identidad se transforma en principio de conflicto político (Wolton, 2004:16). 
De este modo, la comunicación nomadológica debe comprenderse desde dos dimensiones convergentes: a) insubordinación a la normativa imperante respecto a la conformación del plano identitario y cultural; b) como proyección políticocomunicacional.

Para justificar estas dos líneas, los aportes de Browne y Silva referidos a la Antropofagia Cultural y los fundamentos de la Economía Política de la Comunicación, brindan argumentos para sustentar la posición propuesta. Una vez revisados y acoplados a la comunicación nomadológica, se retomará la línea de Wolton.

\section{ANTROPOFAGIA CULTURAL}

Al revisar las obras de Browne (2009) y Browne y Silva (2007, 2004) se reconoce el concepto de antropofagia vinculado a los ámbitos de la comunicación y la cultura, trazando un sistema de pensamiento (in)disciplinario que aboga por la redefinición sustancial de los esquemas analíticos sustentados en el binarismo, para pasar, ahora, a los espacios fronterizo del encuentro cultural y asumir la contaminación sígnica como fenómeno inmanente de todo proceso de interacción cultural.

La antropofagia cultural es la cara crítica de la transculturación como forma de pensamiento fronterizo (Browne y Silva, 2004). Es la aceptación de los espacios intersticios en donde emergen los cruces de semiósferas, desestabilizando la semiosis limitada para -por fin- concebir una semiosis ilimitada, una semiótica de la (inter)cultura que conjuga el encuentro de lo diferente, conformando nuevos espacios semióticos capaces de nutrir el repertorio de sentidos de los sujetos que se reconocen en la interacción cultural.

La mirada de la antropofagia cultural -cuya génesis podría situarse en la revisión que exponen los autores del movimiento antropófago brasileño- emerge como una discursividad que pone en tela de juicio a las sociedades patriarcales que han fundado sus bases en la mirada del otro como sujeto exótico y sus prácticas en la dominación y la exclusión como procesos asociados al poder colonial (Browne y Silva, 2004).

La problemática fundamental que exponen los autores es cómo repensamos las perspectivas culturales y comunicacionales desde un posicionamiento insubordinado, que tienda puentes para la conformación de nuevas identidades que se asuman en el hibridismo, pero consientes de sus diferencias: es necesario revalorizar estas nociones para adaptarlas a las nuevas lecturas híbridas, mestizas y criollas que - pensamosdeberían cuestionar a las identidades cerradas en beneficio de unas identificaciones rizomáticas y plurales. (...) Ésta es la emergencia que aboga por un proyecto de revalorización conceptual que se presenta como un programa de subversión, estimulado por una(s) estrategia(s) de resistencia (Browne y Silva, 2007:83-84). 
No obstante, a pesar del deseo que inhunda un proyecto de desestabilización que opera desde el pensamiento teórico, no es menos cierto que la realidad de la interacción cultural está restringida a la relación dominadores/dominados. Por tanto, se torna necesario seguir abriendo el cauce de la reflexión sobre la comunicación nomadológica, ahora en el sentido del reconocimiento de las condiciones de producción material que delimitan el campo proyectivo de la antropofagia cultural en el seno de las estructuras de dominación latentes en los procesos de encuentro cultural.

La comunicación nomadológica requiere -para su conformación en desplazamiento continuo- recurrir a diversos sistemas teóricos que le permitan nutrir su modo de plantearse como un (a) sistema diferenciado de la misma antropofagia cultural -en la cual reconoce soportes sustanciales para su posicionamiento conceptual y proyectivo-. La comunicación nomadológica no tiene soportes estáticos y no busca ser parte de un único modelo, es parte de todo aquello que permita generar un proyecto de comunicación que ansía al cambio de episteme. Es rizoma en sí misma.

\section{APORTES DE LA ECONOMÍA POLÍTICA DE LA COMUNICACIÓN.}

A modo de ir estableciendo las bases teórico-conceptuales de las condiciones de producción del discurso de la identidad y la alteridad, la revisión de algunos aportes de la Economía Política de la Comunicación brinda elementos a considerar si se busca proponer una síntesis entre la proyección y el reconocimiento de las condiciones reales del ahora respecto a la comunicación entre sistemas culturales diferenciados.

Partamos señalando que la Economía Política de la Comunicación permite abordar la problemática estructural de la comunicación desde una "epistemología realista, inclusiva, constitutiva y crítica" (Mosco, 2006:65). De este modo, brinda las herramientas analíticas necesarias para pensar los fenómenos comunicacionales desde la inserción en las praxis comunicativas y en sus condiciones de producción, circulación y consumo.

En el caso de su cruce con esta propuesta inicial sobre la comunicación nomadológica, interesa en el sentido de su aporte al ámbito de la comprensión de lo comunicacional, lo identitario y lo cultural desde el plano de las influencias que entran en juego al pensar la construcción de la identidad y la alteridad desde la élite institucional, pues como señalábamos al principio, recurriendo a Del Valle, el tema de la comunicación intercultural está afectado por dimensiones de corte político, económico, discursivo y simbólico (Del Valle, 2004a).

Desde la restricción de toda propuesta inicial, a continuación se abogará por situar las influencias de este sistema de pensamiento en su quehacer analítico referido a los 
medios de comunicación de masas, aparatos influyentes en la construcción de la cultura y la identidad en el marco de la aldea global.

Partamos señalando que la Economía Política de la Comunicación establece un cruce con lo "económico y político de la información, la comunicación y la cultura" (Del Valle, 2004b:21), configurándose como un sistema de pensamiento que surge:

A partir de una visión crítica sobre la presencia de los llamados "medios de comunicación de masas" y, en general, de las distintas manifestaciones de "industrias culturales". Este fenómeno será, por cierto, paralelo a la conformación de un sistema particular de relaciones económicas y políticas en nuestras sociedades, el cual tendrá la hegemonía, el control, y la reducción de las relaciones sociales en forma de intercambio de mercancías: el capitalismo (Del Valle, 2004b:21).

Por tanto, la cultura no es un sistema inmanente, debe su manifestación a elementos que articulan relaciones intersistémicas, que en este caso particular se reconocen a partir de los influjos del mercado, lo político y lo massmediático.

Situar el análisis de los medios de comunicación obedece al hecho de asumirlos como aparatos ideológicos que sustentan un modo de pensar la cultura restringida al campo de las decisiones del poder económico y político, aunque todo apunta, producto de la crisis de los Estados nacionales, que hoy en día es el mercado el encargado central de estructurar las lógicas de sentido que promueven los medios de comunicación. En este plano, la cultura pasa por el cedazo homogeneizante del mercado mundial, pues no olvidemos que el capitalismo extiende sus redes mercantiles por el orbe, acaparando lo cultural a través de la globalización económica y comunicacional. Los mass media, por ende, se emplazan en la construcción de una cultura global, invisibilizando o transformando en mercancía de consumo la diferencia cultural. El otro-exótico es absorbido por los medios de comunicación con el propósito de instalarlo en la cultura global como objeto de artilugio antropológico, sin adecuar una mirada de la alteridad que abogue por su autorrepresentación y su convergencia dialógica con los receptores ubicados desde la acera cultural propia de los que dominan la plataforma económica y comunicacional a escala transnacional.

La economía política de la comunicación se caracteriza por tres ámbitos que recoge de la economía política, los cuales deben ser develados para una comprensión crítica de la comunicación como fenómeno asociado a lo político y lo económico:

- Mercantilización: es el proceso de transformar cosas valoradas por su uso en productos comercializables que son valorados por lo que de ellos se puede obtener en un intercambio (...)

- Especialización: es el proceso de trascender los límites del espacio geográfico a través de, principalmente, los medios masivos y las tecnologías de la comunicación (...) 
- Estructuración: es el proceso de crear relaciones sociales, principalmente aquellas organizadas alrededor de la clase social, el género y la raza. (Mosco, 2006:58)

La pregunta a establecer es en qué medida se vinculan estos tres ámbitos con la Comunicación Nomadológica como instancia de interacción entre el "nosotros" y los "otros". Intentemos indagar en ello.

La economía política de la comunicación al indagar en las condiciones de producción, circulación y consumo de lo comunicacional, abre un escenario sistémico respecto al estudio de los procesos comunicativos, capaz de complementar las lecturas asociadas, básicamente, al campo simbólico del fenómeno. La economía política de la comunicación permite reconocer las formas materiales que generan tipos de semiosis particulares en mundos sociales y culturales específicos, aunque, a través de los mecanismos globalizantes, el plural parece ir asumiendo cada vez más un singular como esencia.

Es por tanto que la producción de la identidad y la alteridad estaría reglada por las condiciones materiales fundadas desde la hegemonía política, económica y cultural. Concebir la identidad y la alteridad es parte del entrelazado sistémico que emerge desde la mercantilización, especialización y estructuración. La cultura, tanto la propia como la ajena, está sujeta a la valorización del mercado. El otro es una mercancía condicionada por los intereses económicos que lo sitúan en el escenario de las comunicaciones; el otro es acoplado temporal y espacialmente a los límites de la semiósfera dominante producto de su traslación a las redes massmediáticas que generan el encuentro con la diversidad cultural; el otro es estructurado a partir de lógicas de dominación suscitadas en los espacios hegemónicos de la cultura, la información, la economía, lo político y lo social.

Por tanto, la comunicación monadológica debe hacerse cargo: a) de la aceptación de las contaminaciones sígnicas a las que se está sujeto en todo proceso de encuentro cultural; b) reconocer las condiciones materiales que estructuran el tipo de relación dominadores/dominados. De otro modo, el hibridismo al que se somete el nómade no adquiere potencial político y no se construye desde una dimensión política, sólo pasa por un aglutinamiento de simbólicas sin el debido proceso de identificación del otro como entidad diferenciada.

\section{REARMANDO EL TRIÁNGULO INFERNAL.}

La antropofagia cultural y la economía política de la comunicación nutren a la comunicación nomadológica en su afán de situarse como un sistema de pensamiento que remueva las condiciones de relación simbólica y material que determinan los 
procesos de interacción entre culturas diferenciadas. En este sentido, es, aboga por la reflexión de los planos simbólicos, discursivos, económicos y políticos, emplazando al sujeto de la comunicación nomadológica a un conocimiento de corte estructural respecto a su propio lugar de enunciación como del espacio de enunciación del otro. No basta por un reconocimiento de los elelemntos culturales superficiales, requiere de la elaboración de una competencia comunicacional intercultural, siguiendo a Rodrigo Alsina (2000), que permita reconocer al otro desde los planos materiales y simbólicos, pero también reconocerse al mismo nivel en el marco de la cultura propia.

Cuando Rodrigo Alsina se refiere a la competencia comunicativa intercultural, propone tres competencias que la fundamentan:

- Competencia cognitiva: Conocimiento de los elementos de la cultura receptora.

- Competencia afectiva: permite una capacidad emotiva y motivacional ante los nuevos retos.

- Competencia operacional: capacidad para actuar, permite a los forasteros expresar sus experiencias cognitivas y afectivas. (Rodrigo, 2000:186-187)

Si bien Rodrigo Alsina establece la necesidad de generar una competencia comunicacional que permita reconocer al otro como factor constitutivo del nosotros, éstas también deben redirigirse al espacio de lo propio. No puede haber conocimiento de la otredad sin conocer los elementos que componen la identidad, no puede haber estructuras afectivas hacia el otro sin dirigirlas a lo propio, no puede haber materialzación práctica de éstas sin realizarlas en el marco de la propia cultura. La comunicación nomadológica es el cruce de fronteras, es el espacio intersticio conformado por el encuentro de semiósfera diferenciadas. No es, en ninguna instancia, “aculturación” ni “asimilación” (Bonfil, 1988).

A su vez, el desarrollo de esta competencia no puede pensarse como un automatismo intrínseco del individuo que se enfrenta por sí mismo a la heterogeneidad. Ésta debe estar respalda por un proyecto político estructural, tal como lo plantea García Gutiérrez al momento de pensar las proyecciones de las tecnologías virtuales en el plano de la interacción cultural, proponiendo la conformación de una tecno-ética transcultural que permita direccionar los causes de la relación cultural tanto a nivel técnico como político (García Gutiérrez, 2004).

En el caso de la comunicación nomadológica -en su lucha por redefinir los procesos de intercambio simbólico y por situarse en el análisis de las condiciones materiales de la producción de identidades y alteridades- el proyecto político se concentra en la lectura crítica del triángulo infernal: identidad - cultura - comunicación, considerando que el tecnicismo economicista triunfante del capitalismo debe ser superado por propuestas de corte político-cultural asentadas en la reflexión de las heterogeneidades presentes en el orbe y cuyo encuentro cultural se materializa cada día producto de la expansión de las 
comunicaciones. En este sentido, lo cultural, desde una nueva apuesta política que avale el encuentro de la diversidad cultural, se abre a una organización de acciones que cruzan "la cultura y la comunicación, la economía, la sociedad y la política" (Wolton, 2004:88), a modo de establecer los márgenes de regulación respecto a la primacía de las políticas economicistas que reinan en la escena globalizante del mercado mundial, confiriendo un sentido ético a las comunicaciones desde la base de una axiología fundada en la convivencia cultural como norma transversal de todo proceso comunicativo contextualizado en el encuentro entre la identidad y la alteridad.

Comunicación - Identidad - Cultura son los pilares de la nueva mundialización a la que postula Wolton, otorgándole un sitial preponderante al pensamiento relacional entre culturas diferentes. De otro modo, el encuentro cultural seguirá supeditado a la militarización de la política y al triunfo del mercado por sobre el triunfo de la convivencia cultural. La nueva política que remire el triangulo infernal debe abogar por el establecimiento de redes identitarias que configuren lo que Wolton denomina "identidad cultural colectiva", en la cual se reconocen dos aspectos de impronta:

Por un lado, la mezcla entre culturas en el sentido clásico de patrimonio y la cultura como conjunto de informaciones, conocimientos, instituciones, etc., que son fundamentales para orientarse en el mundo contemporáneo. Por el otro, implica una dimensión colectiva cuyo anhelo es integrar la heterogeneidad de la sociedad. (Wolton, 2004:59)

Es importante destacar que la integración de la hetorogeneidad social depende un hecho político a establecer, en la medida que requiere de las tomas de decisiones que se conglomeren para su concretización.

La identidad cultural colectiva es parte esencial de le comunicación nomadológica, desde el prisma del derrumbamiento de las posturas etnocéntricas a las cuales apunta Todorov (2009). Por un lado, el etnocentrismo nacionalista, del cual la historia expone ejemplos que no vale la pena reiterar; y el etnocentrismo en su tendencia universalista, reduccionismo de la realidad identitaria a una categoría unidimensional (Todorov, 2009). A su vez, la identidad cultural colectiva como componente de la comunicación nomadológica es un afluente conceptual y político que pretende contrarrestar lo que Augé ha denominado "individualización de las cosmologías" (2006), tendencia impuesta por la "crisis de la alteridad" al imponerse el lenguaje de la identidad sobre el otro (Augé: 2006:86)².

La imposición del lenguaje de la identidad, en definitiva, es la imposición de un lenguaje político que busca desestabilizar, anular o invisibilizar supuestas

\footnotetext{
${ }^{2}$ Es interesante el análisis de Augé al respecto. El autor establece: La crisis de la modernidad, en la que algunos ven una crisis de la identidad, podría antes bien atribuirse a que uno de los dos lenguajes (el de la identidad) se impone hoy al otro (el de la alteridad). De manera que esa crisis podría caracterizarse mejor como una crisis de la alteridad (Augé, 2006:86)
} 
ambigüedades y/o conflictos generados por la presencia de la alteridad en el seno de la autorregulación de lo propio. Esto, se suscita a partir del descompromiso político referido al ordenamiento de esquemas que permitan conferir sentido al otro desde una interacción consensuada por la heterogeneidad, no el consenso como delimitación impuesta por algunos.

La individualización de las cosmologías es la pérdida de las relaciones simbólicas con el otro, situación dada por la inserción de las dinámicas homogeneizantes que el mercado ha insertado en el dominio de las responsabilidades individuales para la consecución de las expectativas otorgadas por el capitalismo mundial, dejando fuera el protagonismo de las "cosmologías intermediarias", entendidas como los estamentos que ayudan a conferir sentido a "la visión del mundo" de los individuos.

Augé, al respecto señala: ocurre como si una de las características de nuestra época fuera volver a atribuir a los individuos la responsabilidad de crear los modos de relación con los demás, modos capaces de permitirles vivir y compensar solitariamente el déficit simbólico que acarrea el hundimiento de las cosmologías intermediarias y de sus mediaciones constitutivas (Augé, 2006:87).

Es por tal motivo que la comunicación nomadológica reclama la presencia de una nueva política como instancia reguladora de los componentes del triángulo infernal identidad - cultura - comunicación, la cual debe trascender el plano tecno-económico en el cual se encuentra el triángulo y avalar por el diseño de un plano tecno-ético, considerando que las comunicaciones están supeditadas al dominio las tecnológico y del mercado, sin que exista una propuesta ético-política - no teórica- que devele el funcionamiento del mercado en las comunicaciones, y en particular en la construcción de la identidad y la alteridad.

Rearmar el triángulo infernal es concebir las decisiones políticas por sobre las decisiones del mercado, es conferir validez al otro y trabajar con el otro en la construcción de un proyecto estructural capaza de salvaguardar la convivencia cultural y la relación entre sistemas culturales diferentes, apelando por el reconocimiento del otro desde una perspectiva integradora que permita resolver los conflictos simbólicos y materiales que tienden a la militarización d elas identidades y de la política.

La comunicación nomadológica, en este plano, debe situar su diseño teórico-conceptual y su proyección analítica y performativa en el marco de la integración de las corrientes de pensamiento que han sido capaces de situar el estudio del otro y la convivencia con el otro desde la aceptación, integración y enriquecimiento permanente de la propia identidad. Las propuestas de Leplantine y Nouss sobre el Pensamiento Mestizo (1987), el análisis de García Canclini sobre la comprensión de Latinoamérica más allá de los "universos autosuficientes" impuestos por la modernidad (1995:18), la revisión que Rodrigo Alsina establece sobre el pensamiento relacional postmoderno (2000), la misma propuesta de Wolton sobre la conformación de una identidad cultural colectiva (2004), son algunos de los aportes epistemológicos que la comunicación nomadológica acoge en su proyección como estamento metateórico, pero que debe materializarse en la 
práctica comunicacional de los sujetos que interactuamos desde la identidad a la alteridad a partir del diseño de una política que valorice al otro como parte constitutiva de la toma de decisiones y que resguarde la armonía de las relaciones culturales más allá de los designios del mercado.

\section{CONCLUSIONES}

La comunicación nomadológica es una apuesta germinal que se nutre de diversos sistemas de pensamiento a modo de ir conglomerándose como un modelo de pensar la comunicación entre la diversidad cultural más allá de los dominios mercantilistas y las lógicas de subordinación que han imperado a lo largo de la historia de los contactos culturales.

La comunicación nomadológica problematiza la situación de las comunicaciones desde los planos simbólicos y materiales, a modo de establecer una lectura basada en la complejidad referida a los fenómenos comunicacionales adscritos al diseño de la identidad y la alteridad, aún más cuando se involucra la massmediatización de las comunicaciones al amparo de los mercados informativos-comunicacionales.

La comunicación nomadológica busca presentarse como una reflexión metateórica insubordinada, tanto de los dominios de las praxis comunicativas reconocidas en la relación intercultural como de los esquemas teóricos finitos. Es rizomática y por tanto nunca acabada.

La comunicación nomadológica pretende ser un proyecto para repensar lo político y la política, dialogando fuertemente con la propuesta de Wolton referida a una nueva Mundialización que sostenga la convivencia cultural desde el ordenamiento ético que debiese reconocerse en todo encuentro entre la diversidad cultural. Busca intencionar un debate aún no resuelto.

La comunicación nomadológica es una reflexión permanente sobre lo que somos y lo que se pretende ser desde una indisciplinada comunicacional, cuyo interés es remover los determinismos etnocéntricos y el letargo político existente en los temas referidos a la identidad y la alteridad.

\section{BIBLIOGRAFÍA}

- AUGÉ, M. (2006) Hacia una antropología de los mundos contemporáneos. Sevilla. Gedisa. 
- BONFIL, G. (1988) La teoría del control cultural en el estudio de procesos étnicos. En Papeles de la Casa Chata año 2. No 3. p.p. 23-43

- BOURDiEU, P. (2000) Sobre el poder simbólico. En Intelectuales, política y poder. Trad. de Alicia Gutiérrez, Buenos Aires. Eudeba. pp. 65-73.

- BROWNE, R. (2009): De la comunicación disciplinaria a los controles de la comunicación. La antropofagia como transgresión cultural. Sevilla. Alfar.

- BROWNE, R. y SILVA, V. (2007) Antropofagias. Las indisciplinas de la comunicación. Madrid. Biblioteca Nueva.

- BROWNE, R. y SILVA, V. (2004) Escrituras híbridas y rizomáticas. Pasajes intersticiales, Pensamiento del ENTRE, Cultura y Comunicación. Sevilla. Arcibel.

- GARCÍA, CANCLINI, N. (1995) Culturas Híbridas. Estrategias para entrar y salir de la modernidad. Buenos Aires. Sudamericana.

- Deleuze, G. y GUATTARI, F. (2002) Mil mesetas. Capitalismo y esquizofrenia. Valencia. Pretextos.

- DEL VALLE, C. (2004) Genealogía crítica de la comunicación intercultural. Mediacentrismo e Invisibilización de lo étnico en los estudios interculturales. En Sphera Pública No 4. Murcia, 2004a. p.p. 171-196.

- DEL VALLE, C. (2004) Metainvestigación de la comunicacjón en Chile. Tendencia y Crítica. Temuco, 2004b. Universidad de La Frontera.

- FANON, F. (2009) Los condenados de la tierra. México. Fondo de Cultura Económica. 
- GARCÍA, GUTIÉRREZ, A. (2004) Otra memoria es posible. Estrategias descolonizadoras del archivo mundial. Argentina. La Crujía.

- GREIMAS, A.; FONTANILLE, A. (2002) Semiótica de las pasiones. De los estados de las cosas a los estados de ánimo. Buenos Aires. Siglo XXI S.A.

- GRÜNER, E. (2002) La Tragedia, o el fundamento perdido de lo político. En BORON, A. y DE VITA, A. (comp.) Teoría y Filosofía Política. La recuperación de los clásicos en el debate latinoamericano. Buenos Aires. CLACSO. p.p. 13-50.

- LEPLANTINE, F. y NOUSS, A. (1997) Le Métissage, París. Flammarion.

- MOsCO, V. (2006) La Economía Política de la Comunicación. Una actualización diez años después. Trad. GARCÍA, N. En Cuadernos de Información y Comunicación Vol. 11. p.p. 57-79.

- RODRIGO, M. (2002) La Comunicación Intercultural. Barcelona. Anthropos.

- TODOROV, T. (2009) Nosotros y los Otros. México D.F. Siglo XXI S.A.

- VAN DIJK, T. (2003) Racismo y discurso de las elites. Barcelona. Gedisa.

- WOLTON, D. (2004) La otra mundialización. Los desafíos de la cohabitación cultural global. Barcelona. Gedisa. 